\title{
Crystallographic education in real and reciprocal space
}

\author{
Sisak Jung, D. \\ DECTRIS Ltd., Täfernweg 1, 5405 Baden-Dättwil, Switzerland \\ dubravka.sisak@dectris.com
}

Modern crystallography, as an umbrella of techniques and methods, reaches out to almost everyone interested in the basic question: how are atoms or molecules arranged in a material. This inherent interdisciplinarity of crystallography is further supported by availability of various schools for aspiring crystallographers. On one hand, a well-curated content, good choice of lecturers, and offered sponsorships, make it possible to reach out to students from various backgrounds, interests, regions and economic status. On the other, on-site presence and a good social program ensure interactions between lecturers, students and organizers. Having all this in mind, the success of these schools is not a coincidence. Their interdisciplinarity seems to rely on three factors: content, outreach and interactivity.

In the last year, COVID19 has forced many of crystallographic schools and initiatives to undergo a digital transformation. Emergence of virtual schools has removed many restraints imposed by physical presence in real space: costs, time and geographical limitations, and recruitment of lecturers and speakers. However, it also opened up new questions. What are the needs of a modern researcher/crystallographer? Can crystallography get more interdisciplinary by adopting new fields, such as didactics, communications and economics? Can modern technology be used to enforce interdisciplinarity by improving interactivity, outreach and content?

This presentation looks back to the past and then turns to the future in order to examine possible ways that could be taken to optimize content, outreach and interactivity in both real and virtual schools. Examples are focused on building and maintaining crystallographic communities and include use of social media, industry-academia collaborations, and online interaction tools.

Keywords: crystallography schools; education; crystallography outreach; interdisciplinary science; social media; 